\title{
How to BREAK the Vicious Circle of blame? The contribution of different stakeholders to a more sustainable built environment
}

THOMAS LÜTZKENDORF, PROF. DR.-ING. HABIL.

Karlsruhe Institute of Technology, Department of Economics \& Business Engineering, Sustainable Management of Housing and Real Estate, Karlsruhe, Germany thomas.luetzkendorf@kit.edu

\begin{abstract}
Putting the principles of sustainability into practice within social and economic development requires intensive involvement and participation of the construction, real estate and finance industries. It is necessary that design, construction and refurbishment of buildings are aligned with targets in energyefficiency, resource preservation, climate change and human health. On the one hand design strategies, design tools and construction techniques need further development, but the demand for sustainable buildings needs to increase also.

For a long time market acceptance, market penetration and market transformation of sustainable buildings has been hampered by various obstacles and prejudices. This is now changing because of prove that sustainable buildings have economic advantages, because of social and environmental responsibility being increasingly accepted by all stakeholders, due to developments in law and standardisation as well as due to the example set by the public sector. The vicious circle of blame for low demand for sustainable buildings can therefore be broken. Positive change in the built environment can be brought about by various instruments (laws, standards, grant programmes, market stimulation programmes etc.) as wells as by creating connections between individual and institutional objectives with sustainable development objectives. For those investors interested in sustainable investments, sustainable real estate funds, green REITs can be offered as new investment alternatives.

However, it is equally important to pay greater attention to the social and cultural importance of buildings. Topics such as the interdependence between buildings and life style choices and consumption patterns of building users, the role of buildings within a neighbourhood and urban development, the need to provide adequate accommodation and to create and preserve jobs can also contribute to greater demand for sustainable buildings.
\end{abstract}

Keywords: sustainable building, business case, market transformation, responsible property investment. 

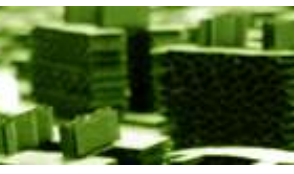

ह

\section{How to BREAK the Vicious Circle of blame? The contribution of different stakeholders to a more sustainable built environment}

\section{Retrospective and Current situation}

Design principles, technologies and construction products for energy efficient, resource efficient and health conscious buildings have been available for decades now. Topics such as design for energy efficiency and the protection of environment and health during construction and operation of buildings have been integrated into education and training for architects and engineers. The same goes for topics such as life-cycle oriented planning, safeguarding economic performance and other building related sustainability issues. In Europe intense academic effort has been put into developing and testing systems for describing, assessing and certifying the sustainability of buildings. Nevertheless the spread of green buildings and sustainable properties encountered resistance and barriers on the real estate market. Already in 2000 this was described as a part of a vicious circle of blame (Cadman 2000).

The vicious circle of blame saw the main reason for resistance and barriers standing in the way of greater spread of sustainable buildings as coming primarily from developers and investors. In particular, stimulating demand for sustainable buildings and interest amongst clients and investors had not succeeded. Some of the causes were:

- The part that the real estate sector played in resource demand and environmental impact had been substantially underestimated.

- Additional expenditure for the design and construction of sustainable buildings had been substantially over-estimated.

- For a long time there was no successful transfer of the term sustainability and the concept of sustainable development into the built environment.

- The value of sustainable buildings for image and reputation had been underestimated.

- The economical advantage of sustainable buildings had not been successfully compiled and proven. There was doubt that investors would be interested in sustainable buildings and willing to pay extra.

- There were hardly any appropriate investment options and products for investors.

Since some years ago the situation has been changing dramatically. Stakeholders in the construction and real estate industry contributed to this transformation in various ways.

The increasing recognition of a responsibility towards environment and society lead to designers increasingly taking on responsibility for the built environment beyond mere 
aesthetics. Consequently, the value of high functional quality (performance based building) was re-discovered, the (concept of the building) life cycle was integrated into the design process and the issue of energy efficiency of buildings were increasingly being addressed.

Under the pressure of impending climate change governments are increasingly looking into issues of mitigation and adaptation. The substantial share in resource consumption, environmental impact and climate change of the real-estate industry has been identified on the one hand. On the other hand the industry's considerable potential of reducing these impacts through a transition to sustainable planning, construction and operation of buildings was also identified. Beyond resource preservation, environmental protection and climate change mitigation the construction industry plays another important role in sustainable development: The industry creates and preserves jobs and contributes to local economy. It contributes qualitatively and quantitatively to sufficient provision of housing. At the same time the built environment is part of cultural heritage. Therefore governments recognise increasingly the economic and social value of the construction and real-estate industries. In many European countries this has led to further developments in and tightening of legal requirements and to the development of grant programmes. Governments act increasingly as role models by integrating sustainability into public procurement ("green public procurement").

The financial crisis and its consequences led in parts of the real estate industry to a change in thinking. It was recognised that risk management needs to be improved and that mid to long term rentability and marketability need to be assured. To this end a building's functional quality, energy efficiency, low life cycle costs, longevity, flexibility and adaptability etc. are key. Alongside the renaissance of the importance of technical and functional qualities, the recognition of economic advantages of green buildings and sustainable properties emerged. At the same time non-sustainable buildings become a risk to reputation for many companies. Hence for many companies sustainability standards for the buildings they occupy is part of company policy.

Sustainable building research is no longer restricted to the progression of design principles, new technologies and construction techniques and the progression of in-use management processes (facility management). Sustainable buildings have also been a key subject of real estate research. There are now large scale surveys that analyse the interests, motives and demands of investors and those in charge of a company's own building stock (corporate real estate managers) and those of fund initiators etc. Rental and sales potential of energy efficient and sustainable buildings are being investigated as well as the readiness of 
tenants and buyers to reward better quality of such buildings by paying higher sale prices or higher rents. Furthermore whether and how sustainable real estate funds or green Real Estate Investment Trusts (green REIT's) offer better performance in comparison with comparable investment products is being investigated.

The activities of the international standardisation (e.g. ISO TC 59 SC 14 and SC 17) and European standardisation (CEN TC 350) helped to harmonize differing notions on how to transfer sustainable development principles to buildings. There is now a high level of consensus that sustainable buildings have to demonstrate not only good performance environmentally, economically and socially, but that they also need to show high levels of performance in terms of architectural and urban design and in terms of functional and technical quality. In so far the integration of sustainability issues into the overall quality of a building ("integrated building performance") has succeeded.

The pre-conditions for greater demand for sustainable buildings and greater market penetration have improved noticeably, but are not yet satisfactory. Further necessary steps are explained in Section 2.

\section{Activities and measures to strengthen demand for sustainable buildings}

Necessary activities and measure to increase the demand for sustainable buildings in the following areas:

\subsection{Improving the way sustainability in buildings is described and assessed}

If the market position of sustainable buildings is to be improved, it must first be possible to describe, assess and illustrate their contribution to sustainable development by means of a transparent and recognised procedure. In the last few years, the available systems for assessment and certification, including the awarding of labels and certificates, have undergone further development. While these systems originally concentrated on energy, environment and health, and were focused on describing and assessing the fundamental technical components of the building, they have since been superseded by a second generation. Through use of environmental accounting and life cycle costing, these systems operate based on the method of life cycle assessment and do not only factor in the ecological and social dimensions but also the economic dimension. They are supplemented by 
assessment results relating to technical and functional quality and are in conformity with the draft of a new standard, currently under development by the European Committee for Standardization, Technical Committee "Sustainability of Construction Works" - CEN TC 350 see

http://www.cen.eu/cen/Sectors/TechnicalCommitteesWorkshops/CENTechnicalCommittees/P ages/default.aspx.

It is the author's view that the second generation of assessment and certification systems, which include the new German Certificate for Sustainable Buildings (DGNB Deutsches Gütesiegel Nachhaltiges Bauen and BNB - Bewertungssystem Nachhaltiges Bauen - see also www.nachhaltiges bauen.de), will make it easier to estimate future leasability and marketability by detailing technical and functional quality and to assess costeffectiveness by detailing life cycle costs. In this regard, it is now possible to address questions over property investment returns directly.

With the EU's 'SuPerBuildings' project (see also http://cic.vtt.fi/superbuildings/) and the activities of the SB Alliance network (see also http://www.sballiance.org/), work on the further development and completion of an assessment and certification solution for sustainable buildings is also being undertaken at European level.

Beyond the progression of assessment and certification systems there is also an urgent need to analyse and optimize the building performance in use (through post occupancy evaluation and continuous improvement). It would be advisable to summarize all essential qualities, properties and data in the format of a building file, which can be supplemented throughout the life cycle. This data would be continuously updated. In so far such a file differs from certification, which just provides a snap-shot at a given point in time.

\subsection{Green public procurement for public buildings}

Although the public sector would incorporate traditional issues of environmental protection (COM 2004a), health and safety into its invitations to tender for construction work and its decision to allocate contracts, there was often a lack of solid guidance and assessment benchmarks. This situation has completely changed since several years.

In many countries, the public sector is trying to play an even stronger leading role in the implementation of sustainable development principles in the construction and property industries, including properties for own use. Laws and regulations are being drafted, funding 
programmes are being developed, requirements for spatial development, urban development and individual buildings are being integrated into national sustainability strategies, and sustainability issues are being taken into consideration as part of public procurement, including in the invitation to tender for construction work and the allocation of contracts. In the process, the basis for assessing the cost-effectiveness of a package of measures often shifts from assessing investment costs to determining and evaluating life cycle costs.

Green public procurement (also environmental public procurement, eco-purchasing or green purchasing) is an instrument for leveraging the market power of the public sector as a contracting party (consumer) in order to strengthen demand for environmentally friendly (sustainable) goods and services. In this context this concerns appropriate planning, construction and management services, construction products and buildings. It involves the integration of, for example, the requirements of environmental protection, health and safety and resource preservation (sustainability) into the processes by which tenders for planning and construction work are invited and contracts are awarded. At the same time, these requirements must be precisely formulated in such a way that they can be identified and implemented by the tenderer and checked for compliance by the contracting party. Attention is drawn to the need for complexity management arising from compliance with technical and functional requirements on the one hand, and the ability to assess the ecological and economic advantageousness of the solution on the other hand. The handbook on environmental public procurement of the EU (COM 2004a) proposes the following steps:

- Development of green purchasing strategies

- Organisation of public procurement

- Formulation and definition of the requirements of the contract

- Selection of suppliers, service providers or contractors

- Awarding the contract

- Formulation of contract performance clauses.

\subsection{Corporate Social Responsibility (CSR) and sustainability reporting}

In connection with a social change in values, the use of sustainable properties is increasingly helping to build a positive image. It is a means by which stakeholders can demonstrate their heightened awareness of their responsibility to the environment and society (CSR). Planners and building contractors as well as investors and companies, whether they 


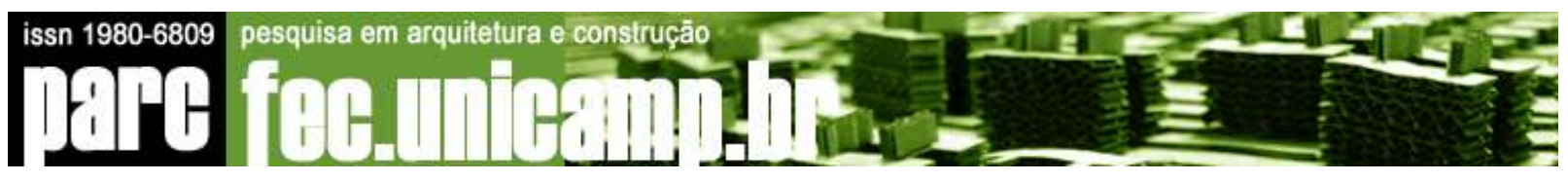

own or rent their properties, are capitalising on this situation and are establishing additional tie-ins with their corporate sustainability reporting framework.

A sector supplement for sustainability reporting in the construction and real estate sector is currently being developed for GRI (Global Reporting Initiative). This will provide a general basis for sustainability reporting (GRI 2010).

\subsection{Analysis and evidence of economic advantages}

Yet, sustainable buildings are also increasingly proving to be less risky, more stable in value and quicker and easier to rent and sell. They facilitate access to land and funding and, in the best case scenario, more favourable financing and insurance terms. In this respect, the rise in demand for sustainable properties can, in the case of some stakeholders, be increasingly attributed to financial reasons. However, the financial advantageousness of sustainable properties is not always empirically verifiable, but the results of initial studies do point in this direction (Eichholtz et.al. 2009); (Fuerst \& McAllister 2009); (Dermisi 2009).

As a transitional arrangement the economic advantages of sustainable buildings can be described qualitatively - see Figure 1. It is evident that the advantages need to be analysed from the point of view of the respective stakeholders (e.g. Landlord or tenant). 

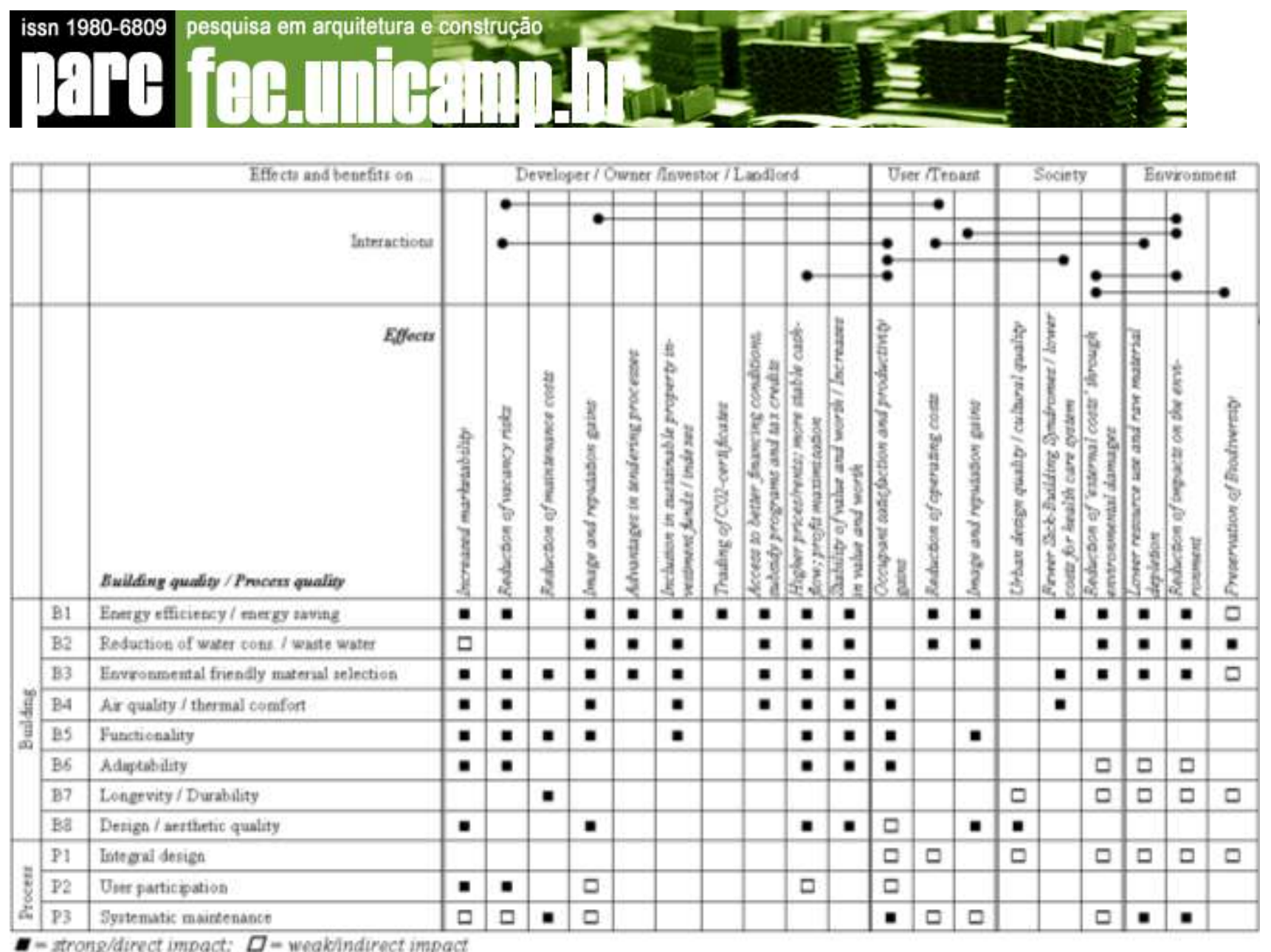

Figure 1 Effects and benefits of sustainable buildings (Lützkendorf, Lorenz 2010)

\subsection{Development of new products for responsible property investment}

Investors (e.g. pension funds) are increasingly interested in sustainable investment opportunities, or, on the basis of existing rules, are obliged to be interested and prove to be so. For indirect property investments, this is leading to demand growth in sustainable property funds. The first providers and products can be seen entering the market, with tendency for growth (Rohde \& Lützkendorf 2009). The development of such products is, in turn, strengthening the demand for sustainable buildings in order to launch corresponding fund products and to provide them with the appropriate properties.

\subsection{Policy instruments}

'Sustainable construction' is one aspect of the Lead Market Initiative (LMI) for Europe (http://ec.europa.eu/ enterprise/policies/innovation/policy/lead-market-initiative/). The LMI provides a methodology to identify promising emerging markets and to support them through 
a package of coordinated innovation-friendly policy actions that would facilitate growth in the demand for innovative goods and services. The action plans deploy a core set of policy instruments (legislation, public procurement, standardisation, labelling and certification and complementary instruments. The following actions are envisaged: screening of national building regulations, industrial leader panel on cumulative administrative costs/benefits, guidance and pilot schemes on award criterion and LCC use, establish a network between public authorities in charge of procuring sustainable construction, framework \& assessment method and benchmarks for the assessment of sustainability performances, Eurocodes 2nd generation, Construction Products Regulation and sustainability requirements, small and medium enterprises (SME's) guide on collaborative working schemes in construction projects, alternative warranty/label schemes related to construction insurance, EU-wide strategy to facilitate the upgrading of skills and competence in the construction sector.

\subsection{Progressing methods for valuation/appraisal and risk analysis}

In terms of integrating sustainability issues into methods for risk analysis, property analysis and property rating, the first steps have been taken with the incorporation of ecological sustainability (TEGoVA, 2003).

In the mean time such methods have developed further and are now being used by banks and rating agencies (Lützkendorf \& Lorenz, 2007). Figure 2 shows how property and market risks of a building can be reduced through sustainability features. 

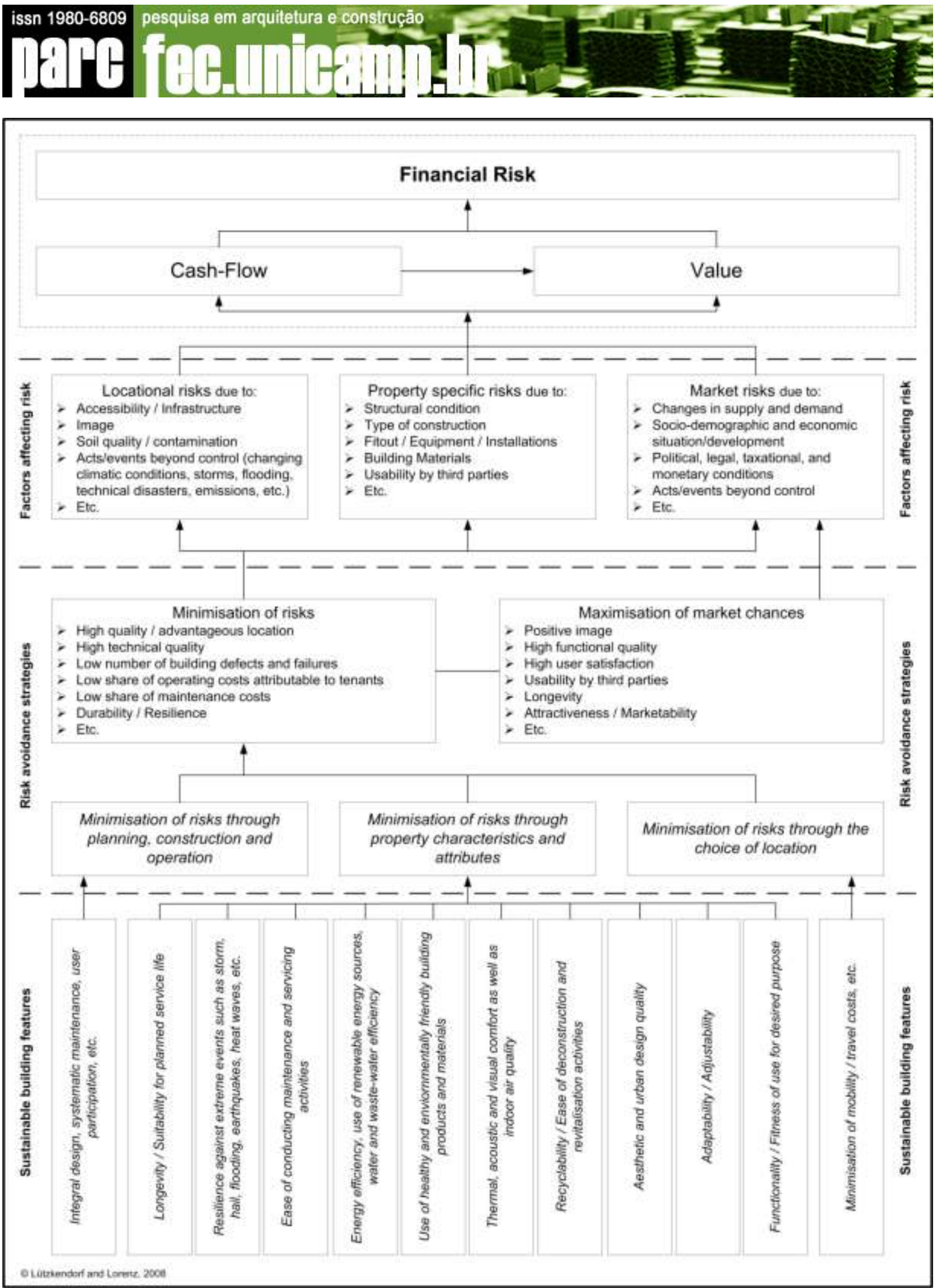

Figure 2 Relationships between property features and financial risks (Lützkendorf, Lorenz 2008) 
The issue of integration of sustainability issues into valuation is subject of intensive scientific discussions and debate, e.g. (Lorenz, 2006), (Ellison et.al 2007), (RICS, 2009), (Meins et.al. 2010) (Muldavin, 2010).

It is evident that in particular the energy efficiency of buildings will be accounted for in valuation. The way of accounting for it depends on the valuation methods used. Not all features of sustainable buildings influence financial risk and economic value directly. In so far the results of sustainability assessment cannot be transferred (translated?) directly. However they provide an essential information base, as long as the results for individual criteria are available in disaggregated form. "Job-sharing" between sustainability assessments and property valuation are currently being discussed intensely. (JSBC, 2009)

\subsection{Financing of sustainable buildings}

As early as 2004, the European Commission expressed its hope and expectation that certification of the sustainability of buildings combined with an illustration of their economic benefits would result in increased demand and greater willingness to pay on the part of purchasers and tenants as well as more favourable terms in the financing and insuring of these types of property (COM, 2004b). The question is thus whether, and to what extent, banks and insurers will recognise and appreciate the economic benefits associated with sustainable buildings. More favourable financing and insurance terms would then be seen as another advantage, which would in turn contribute to a strengthening of demand. To date, however, any examples are few and far between and can be classified by type as follows:

- Banks (KfW in Germany, for example) that act as 'economic development banks' and conduct development programmes on behalf of the state using public funds.

- Banks that, as part of a marketing campaign or an awareness of their responsibility to the environment and society, grant special offers valid for defined, individual measures for a limited period of time (usually cheaper interest rates for measures related to energy conservation)

- Banks that specialise in the financing of measures for environmental protection and sustainability

- Banks that are aware of the reduced energy and running costs of sustainable buildings and take this into account when assessing the creditworthiness of the borrower (e.g. for single-family homes) and the amount of credit to give (e.g. energy efficient mortgage). 
- Banks that, as part of project financing, grant more favourable terms in recognition of the economic benefits of sustainable buildings (or demand risk surcharges for non-sustainable properties) after having weighed up the property risks

Only in the last example there is a direct relationship between financing terms and recognition of economic benefits as part of property and risk assessments and estimates of performance and probabilities of failure. Subsequent analysis focuses on this relationship. For further steps in this desired direction, the following questions need to be clarified in terms of which prerequisites are created:

Can the contribution of buildings to sustainable development be described and evaluated in a transparent, auditable and recognised manner? This necessitates, for example, further development of assessment and certification systems and of criteria grids and benchmarks.

Which attributes and characteristics of sustainable buildings have a direct or indirect impact on the financial risks and prospects of property? Identification of 'success factors' is required.

Can sustainability issues be integrated into property and risk analyses and value appraisals and can their positive effects be illustrated? This requires the further development of appropriate methods and instruments.

Can the greater willingness to pay for sustainable buildings on the part of tenants and investors be proven empirically? For this to be possible, the way in which buildings are described and transaction data are evaluated must be improved.

In Germany, banks and mortgage providers are discussing intensively whether and how financing conditions for sustainable buildings co be improved. Higher lending values, that can lead to higher credit volumes with more favourable condition, as well as lower interest rates are being discussed.

\subsection{Further steps}

The subject of 'green building' and 'sustainable property' has taken hold in the property industry. Growing demand, also in connection with new products such as 'sustainable property funds', can already be observed. This demand can be strengthened further by the purposeful alignment of public procurement with the principles of sustainable development, 


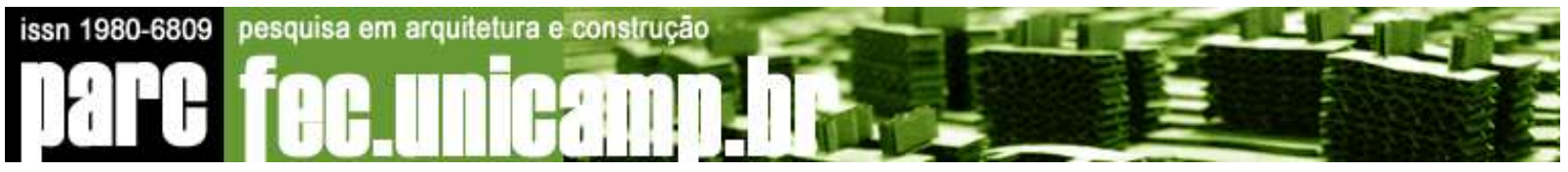

the further development of framework conditions (laws, regulations, standards, funding programmes) and the use of market mechanisms. Prerequisites include:

- Further development of systems and tools for describing and assessing buildings and their harmonisation

- Improvement of the empirical basis through the surveying and publishing of transaction data, supplemented by the fundamental attributes and characteristics of properties

- Extension of empirical studies to provide evidence of the environmental advantageousness of sustainable buildings, e.g. by determining the relationships with financial risks and value performance

- Development and dissemination of tools to aid the tender invitation process

- Integration of sustainability-relevant information about products, designs and buildings into the tender documents

- Integration of sustainability issues into Public Private Partnership (PPP)- and Private Finance Initiative (PFI)- models.

\section{Summary}

The increase in demand for sustainable buildings and the further market transformation require the involvement and participation of many stakeholders. It is only in this way that the basic principles can be developed for demonstrating the advantages of sustainable buildings (risk management, valuation), that financing and grant conditions can be shaped, that new products can be created (sustainable real estate funds, green REITs), and that project developers can be won over.

Figure 3 summarised the most important stakeholders and their possible contributions in terms of support for the implementation of principles of sustainable construction in the construction and real-estate industry. 


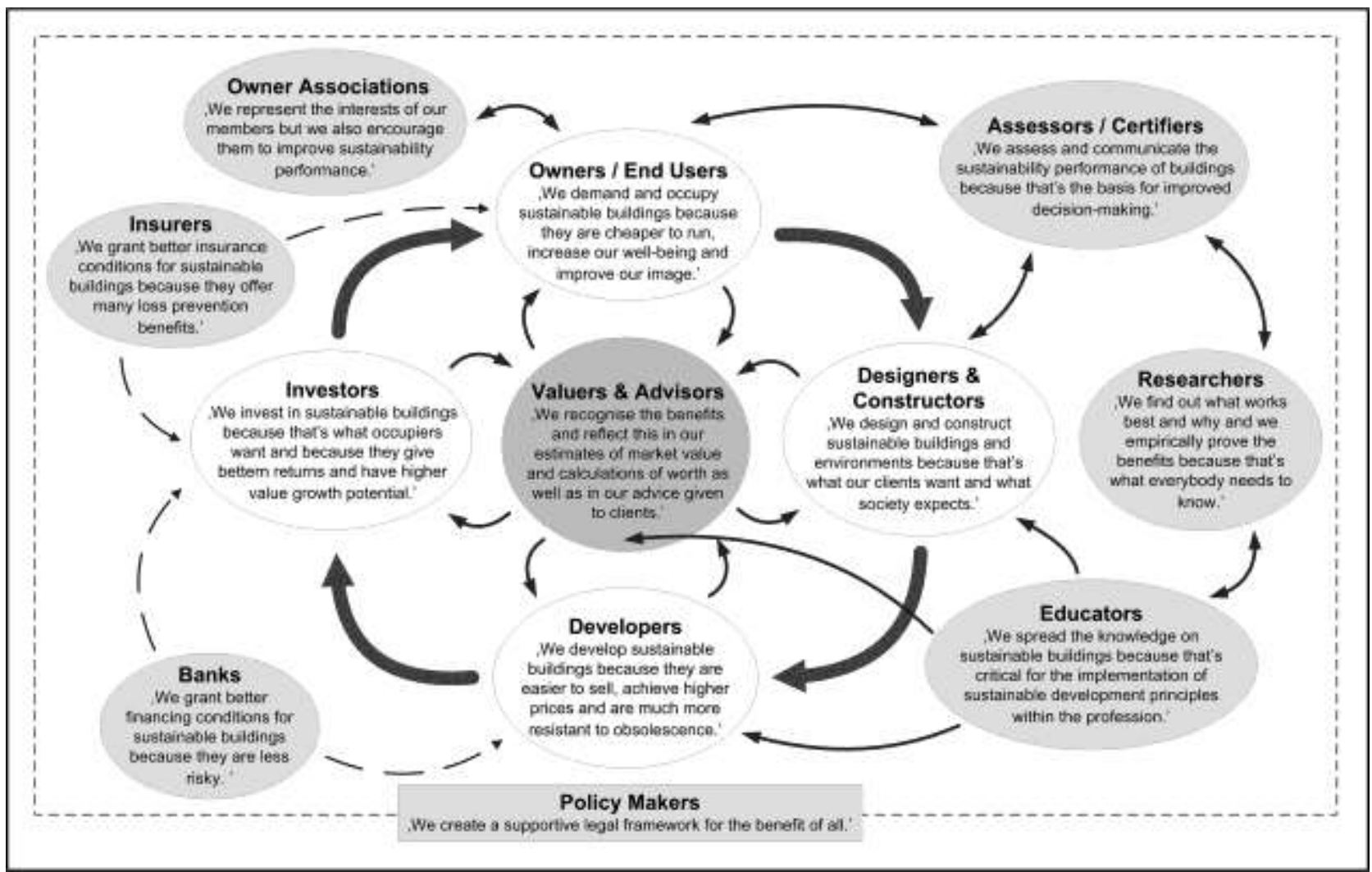

Figure 3 How to break the vicious circle of blame (Lorenz and Lützkendorf, 2008 in RICS 2008)

Crucial stakeholders of the real estate industry have mainly financial interests. It is therefore critical that a business model for the financing of sustainable properties be developed and at the same time that the interest amongst investors be sparked.

It is the author's view that the efforts to integrate sustainability issues into risk analysis and portfolio management, valuation, financial decision making and defining financing conditions need to be intensified. In this way the forces of the market can be used best in order to strengthen the demand for sustainable properties.

It remains the responsibility of the state to provide a framework for the market forces. There continues to be a need for defining environmental and health protection by legal means. Through grant programmes and acting as role model the state can make further important contributions.

Research can and must contribute to further development of the methods for description and assessment of properties. There is currently great demand for empirical evidence for economic advantages of sustainable buildings. 
It is the responsibility of educational institutions to equip future managers of the construction and real estate industry, as well as planners, architects and engineers with the knowledge that is necessary for the implementation of the principles of sustainable development within the construction and real estate industry.

\section{References}

Cadman, D. 2000. The vicious circle of blame. Cited in: Keeping, M. 2000, What about demand ? Do investors want sustainable buildings ? The RICS Research Foundation

COM - Commission of the European Communities. 2004a, Buying green - a handbook on environmental public procurement, Brussels, SEC (2004) 1050

COM - Commission of the European Communities. 2004bm Towards a thematic strategy on the urban environment. COM (2004) 60 final

Dermisi, S. 2009, Effect of LEED ratings and levels on office property assessed and market values. The Journal of Sustainable Real Estate. Vol. 1/2009 : 23-48

Eichholtz, P.; Kok, N.; Quigley, J. 2009, Doing well by doing good ? An analyses of the financial performance of green office buildings in the USA. RICS Research Report 3/2009

Ellison, L.; Sayce, S.; Smith, J. 2007, Socially Responsible Property Investment: Quantifying the relationship between Sustainability and Investment Property Worth. Journal of Property Research, Vol. 24, No. 3: 191-219

Fuerst, F. \& McAllister, P. 2009, An investigation of the effect of eca-labeling on office occupany rates. The Journal of Sustainable Real Estate. Vol. 1/2009 : 49 - 64

Frensch, S. 2008. Green Building - ist Zertifizierung für Sie ein Thema ?, Ernst \& Young Real Estate

GRI - Global Reporting Initiative. 2010, Sustainability reporting guidelines Construction and real estate supplement, draft

JSBC - Japan Sustainable Building Consortium. 2009, CASBEE for property appraisal

Lorenz, D. 2006, The application of sustainable development principles to the theory and practice of property valuation. Karlsruher Schriften zur Bau, Wohnungs- und Immobilienwirtschaft, Band 1. Universitätsverlag Karlsruhe

Lorenz, D., d'Amato, M., Des Rosiers, F., van Genne, F., Hartenberger, U., Hill, S., Jones, K., Kauko, T., Kimmet, P., Lorch, R., Lützkendorf, T. and Percy, J., 2008, Sustainable Property Investment \& Management - Key Issues and Major Challenges, Published by: Royal Institution of Chartered Surveyors, London 


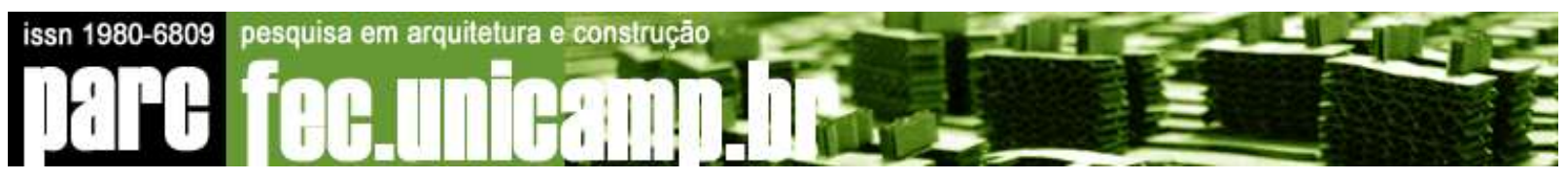

Lützkendorf, T., Lorenz, D. 2007, Integrating sustainability into property risk assessment for market transformation, Building Research and Information, 35(6), pp 644 - 661

Lützkendorf, T., Lorenz, D. 2008, Sustainable building features linking through to assessments of risk, Cited in: Lowe, C.; Ponce, A.; Larsson, N.; Lorenz, D.; Lützkendorf, T.; Moro, A.; Prior, J. 2009. UNEP-FI \& SBCl's financial \& sustainabvility metrics report - an international review of sustainable building performance indicators and benchmarks

Lützkendorf, T., Lorenz, D. 2010, Socially responsible property investment background, trends and consequences, in : Global Trends in Real Estate Finance, WileyBlackwell, 1010, pp 194 - 237

Meins, E., Burkhard, H. 2009, Der Nachhaltigkeit von Immobilien einen finanziellen Wert geben - ESI. Center for Corporate Responsibility and Sustainability at the University of Zurich

Meins, E., Wallbaum, H.; Hardziewski, R., Feige, A. 2010, Sustainability and property valuation: a risk-based approach, Building Research and Information, 38(3), pp 280 - 300

Muldavin, S., 2010, Value beyond cost savings - How to underwrite sustainable properties, Green Building Finance Consortium

RICS - Royal Institution of Chartered Surveyors. 2008, Breaking the vicious circle of blame - making the business case for sustainable buildings. FiBRE, RICS Research

RICS - Royal Institution of Chartered Surveyors. 2009, Valuation Information Paper No. 13 - Sustainability and commercial property valuation

Rohde, C. \& Lützkendorf, T. 2009, Step-by-step to sustainable property investment products. The Journal of Sustainable Real Estate. Vol. 1/2009 : pp $227-240$

TEGoVA - European Group of Valuers' Association. 2003, European property and market rating - a valuer's guide 